\title{
Intoxicação por veneno de sapo em um canino
}

\author{
Toad venom intoxication in a dog
}

\author{
Luciana Sonne $^{\mathrm{I}}$ Daniela Bernadete Rozza ${ }^{\mathrm{II}}$ Adriana Nunes Wolffenbüttel ${ }^{\mathrm{II}}$ \\ Adriana Erica Wilkes Burton Meirelles ${ }^{\mathrm{I}}$ Pedro Miguel Ocampos Pedroso $^{\mathrm{I}}$ \\ Eduardo Conceição de Oliveira ${ }^{\mathrm{I}}$ David Driemeier $^{\mathrm{I}}$
}

\begin{abstract}
O sapo do gênero Bufo possui nas suas glândulas paratóides uma secreção mucóide contendo toxinas como bufaginas e bufotoxinas, que são esteróides cardiogênicos. Os cães podem atacar os sapos, entrando em contato com o veneno por meio das mucosas. Um canino, da raça Bulldog Francês, foi encaminhado ao Setor de Patologia Veterinária da Universidade Federal do Rio Grande do Sul (UFRGS) para a necropsia com histórico de provável intoxicação por veneno de sapo. Na necropsia o canino apresentava pulmões aumentados de volume, avermelhados e com edema, e rins de coloração vermelho-escura. As alterações microscópicas indicaram congestão, hemorragia e edema pulmonar. Nos rins, no baço e nos linfonodos foi observada congestão. As análises toxicológicas para os venenos de rotina foram negativas. Porém, a investigação do veneno de sapo a partir de cromatografia por camada delgada e gasosa demonstrou resultado positivo, revelando ser esta a causa da morte do canino.
\end{abstract}

Palavras-chave: Bufo, veneno, canino.

\section{ABSTRACT}

The toads of the genus Bufo produce, in their parotoid glands, a mucoid secretion containing toxins such as bufagins and bufotoxins, which are cardiogenic steroids. The mucous membranes of dogs can absorb this venom when they attack the toads. A French bulldog with a history of probable toad venom intoxication was referred to Veterinary Pathology Section of Federal University of Rio Grande do Sul (UFRGS) for necropsy. The necropsy revealed enlarged, reddish, edematous lungs, and kidneys displaying a dark red color. The microscopic alterations indicated the presence of congestion, hemorrhage, and pulmonary edema. Congestion was observed in the kidneys, spleen and lymph nodes. The routine toxicological analyses for venom detection were negative. Nevertheless, the toad venom test result was positive as assessed by thin layer and gas chromatography, indicating that toad venom intoxication was the cause of death.

Key words: Bufo, venom, dog.

O sapo do gênero Bufo possui distribuição mundial, porém, existem mais espécies em áreas de clima tropical e úmido, existindo mais de 200 espécies de Bufo em todo o mundo (ROBERTS et al., 2000; SAKATE \& OLIVEIRA, 2001). Como mecanismo de defesa contra seus predadores, o sapo do gênero Bufo possui glândulas paratóides localizadas na região posterior à órbita ocular que produzem e estocam um líquido mucoso e esbranquiçado (SAKATE \& OLIVEIRA, 2000). Os cães atacam os sapos causando a compressão das glândulas com conseqüente eliminação do veneno, que entrará em contato com a mucosa oral e pele não integra. A absorção das toxinas pela mucosa oral e gástrica ocorre rapidamente (PALUMBO et al., 1975). A secreção das glândulas paratóides contém toxinas como as bufogeninas, as bufotoxinas, as bufoteninas,

ISetor de Patologia Veterinária, Universidade Federal do Rio Grande do Sul (UFRGS). Av. Bento Gonçalves, 9090, Agronomia, 91540-000, Porto Alegre, RS, Brasil. E-mail: davetpat@ufrgs.br.*Autor para correspondência.

"Setor de Patologia Veterinária, Universidade Estadual Paulista Júlio de Mesquita Filho (UNESP), Araçatuba, São Paulo, Brasil.

"I'Laboratório de Análises Toxicológicas (LATOX), Porto Alegre, RS, Brasil. 
a epinefrina, a serotonina, o ergosterol, o colesterol e a 5-hidroxitriptamina (PALUMBO et al., 1975; BARRAVIERA et al., 1999). A ação das bufogeninas e bufotoxinas, que são esteróides cardioativos, resulta na fibrilação ventricular como visto nas intoxicações por digitálicos (PALUMBO et al., 1975). Adose letal de bufotoxina foi de $100 \mathrm{mg}$ da toxina para um cão entre nove e 14kg (ROBERTS et al., 2000). O maior risco de intoxicação ocorre no verão, na primavera e no outono durante a noite e após as chuvas (RODER, 2003). Como o hábito alimentar dos sapos é noturno, o envenenamento ocorre geralmente nesse período, dificultando assim a identificação do início do aparecimento dos sinais clínicos pelo proprietário (GODOY et al., 2005).

Os sinais clínicos incluem hipersalivação, mucosas hiperêmicas, apatia, vômitos, ansiedade, cegueira, taquipnéia e dor abdominal. Os animais podem apresentar sinais nervoso, incluindo convulsões, ataxia, nistagmo, opistótomo, estupor e coma (ROBERTS et al., 2000). A morte destes cães está relacionada ao efeito cardiotóxico do veneno levando à morte por fibrilação ventricular(OSWEILER, 1995; SAKATE \& OLIVEIRA, 2000). A manifestação dos sinais clínicos se dá rapidamente após a intoxicação, sendo que a morte pode ocorrer 15 minutos após o aparecimento dos sinais clínicos (SAKATE \& OLIVEIRA, 2001).

O diagnóstico da intoxicação por veneno de sapo se baseia nos sinais clínicos e no histórico (OSWEILER, 1995). O diagnóstico diferencial envolve ainda intoxicações com metaldeído, cáusticos, inseticidas e anticolinesterásicos (NICHOLSON, 1995). $\mathrm{Na}$ necropsia são observadas alterações como hemorragias e congestão em diferentes órgãos. $\mathrm{O}$ diagnóstico definitivo de intoxicação por veneno de sapo ocorre pela identificação da toxina no cão acometido, uma vez que os achados de necropsia são inespecíficos, mas a pesquisa do veneno não é uma técnica rotineira (OSWEILER, 1995).

Para o tratamento preconiza-se a administração de sulfato de atropina e propanolol podendo-se ainda utilizar lidocaína ou verapamil para o controle das arritmias. No entento, o tratamento deve ser efetuado rapidamente, tendo em vista a gravidade da intoxicação (PALUMBO et al., 1975; NICHOLSON, 1995). Autilização de fragmentos Fab específicos para digoxina foi testada com resultados positivos, uma vez que a maioria dos pacientes intoxicados com o veneno do sapo tem altas concentrações de esteróides similares a digoxina (BRUBACHER et al., 1999; GOWDA et al., 2003).

Foi encaminhado para o Setor de Patologia Veterinária da UFRGS um canino, fêmea, da raça Bulldog Francês, com dois anos e seis meses. Com base no relato fornecido pelo proprietário do cão, este foi encontrado morto e sem apresentar sinais clínicos anteriores. A necropsia do canino foi realizada e fragmentos de órgãos fixados em solução de formalina $10 \%$, sendo estes processados por técnicas rotineiras de histopatologia. O conteúdo gástrico, o estômago, o fígado e os rins foram coletados para a análise toxicológica. Como a análise da toxina presente no veneno de sapo não é uma técnica rotineira, foi coletada a secreção mucóide das glândulas paratóides de um sapo do gênero Bufo para a possível detecção da toxina no canino (Figura 1).

A metodologia de análise toxicológica baseou-se no método Stas-Otto, que consiste na extração da fase aquosa do material biológico em pH alcalino e em $\mathrm{pH}$ ácido, com solventes orgânicos. O extrato resultante é submetido à cromatografia em camada delgada (CCD) em cromatoplacas de sílica gel e por cromatografia gasosa com detector de ionização de chama (CG-FID, Cromatógrafo HP 5890 II, Coluna Capilar BP 624-30m).

Na necropsia o cão apresentava bom estado corporal, mucosas ocular e oral congestas e presença de grande quantidade de saliva na boca. Os pulmões se apresentavam avermelhados e com edema, os rins estavam vermelho-escuros e o estômago repleto de ração digerida. Na microscopia havia hemorragia, congestão e edema pulmonar, e congestão no baço, nos rins e nos linfonodos. No exame macroscópico e microscópico as alterações foram inespecíficas, porém esses achados são comumente encontrados em diferentes tipos de intoxicações. As análises toxicológicas foram negativas para a detecção de cumarínicos, arsênico, estricnina, organofosforados, carbamato, cianeto e nitritos. No ambiente onde o animal habitava, eram encontrados sapos do gênero Bufo e por isso se desconfiou de um possível envenenamento pelo veneno do sapo. A análise toxicológica pôde ser conclusiva por meio da utilização como padrão de referência o veneno retirado das glândulas do sapo. O que foi confirmado pela cromatografia em camada delgada direcionada para alcalóides e pela cromatografia gasosa.

O cão neste caso possivelmente atacou um sapo do gênero Bufo e houve a liberação do veneno e o contato deste com as mucosas do canino. Após a absorção das toxinas, o animal provavelmente apresentou sialorréia, quadro convulsivo e arritmia. As alterações macroscópicas e microscópicas foram sugestivas de envenenamento, porém a intoxicação não ocorreu por venenos comumente pesquisados. Diante de um histórico de morte rápida e achados patológicos compatíveis com um quadro tóxico, a intoxicação por veneno do Bufo deve ser considerada. 


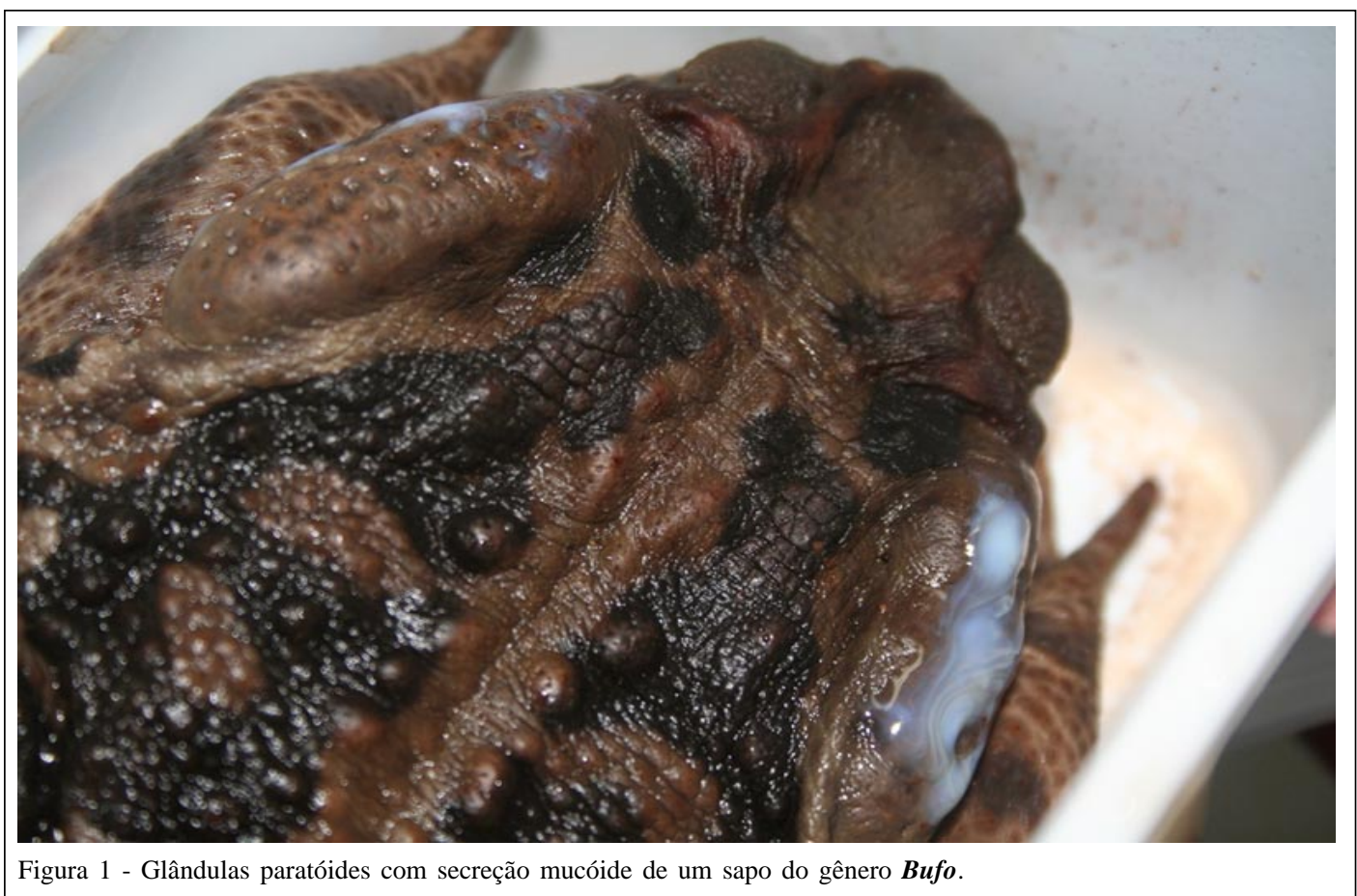

\section{REFERÊNCIAS}

BARRAVIERA, B. Aspectos clínicos e terapêuticos dos acidentes por animais peçonhentos. In: MONTI, R.; CARDELLO. L. Bioquímica do veneno de anfíbios. Rio de Janeiro: EPUB, 1999. p.225-232.

BRUBACHER, J.R., et al. Efficacy of digoxin Fab fragments $\left(\right.$ Digibind $^{\circledR}$ ) in the treatment of toad venom poisonig. Toxicon, v.37, p.931-942, 1999.

GODOY, L. et al. Toxicidad de la secreción de glândulas parotidas en sapo (Actualización Bibliográfica). Universidad Nacional Del Nordeste Comunicaciones Científicas y Tecnológicas 2005, v.20, 2005.

GOWDA, R.M. et al. Toad venom poisoning: resemblance to digoxin toxicity and therapeutic implications. Heart, v.14, n.89, p.483-485, 2003.

NICHOLSON, S.S. Toxicologia. In: ETTINGER, S.J.; FELDMAN, E.C. Tratado de medicina interna veterinária. São Paulo: Manole, 1995. Cap.61, p.460.
OSWEILER, G.D. Toxicology. Philadelphia: Lippincott Willian \& Wilkins, 1995. 443p.

PALUMBO, N.E. et al. Experimental induction and treatment of toad poisoning in the dog. Journal of American Veterinary Medical Association, v.167, n.11, p.1000-1004, 1975.

ROBERTS, B.K. et al. Bufo marinus intoxication in dogs: 94 cases (1997-1998). Journal of American Veterinary Medical Association, v.216, n.12, p.1941-1944, 2000.

RODER, J.D. Toads. In: PLUMLEE, K.H. Clinical veterinary toxicology. Missouri: Mosby, 2003. 113p.

SAKATE, M.; OLIVEIRA, P.C.L. Toad envenoming in dogs: effects and treatment. Journal Venomous Animals and Toxins, v.1, n.6, p.53-62, 2000.

SAKATE, M.; OLIVEIRA, P.C.L. Use of lidocaine, propranolol, amidarone and verapamil in toad envenoming (genus Bufo) in dogs. Journal Venomous Animals and Toxins, v.2, n.7, p.240-259, 2001. 